\title{
Efficacy and acceptability of mood stabilisers in the treatment of acute bipolar depression: systematic review
}

\author{
Ryan J. Van Lieshout and Glenda M. MacQueen
}

\section{Background}

Although people with bipolar disorder spend more time in a depressed than manic state, little evidence is available to guide the treatment of acute bipolar depression.

\section{Aims}

To compare the efficacy, acceptability and safety of mood stabiliser monotherapy with combination and antidepressant treatment in adults with acute bipolar depression.

\section{Method}

Systematic review and meta-analysis of randomised, doubleblind controlled trials.

\section{Results}

Eighteen studies with a total 4105 participants were analysed. Mood stabiliser monotherapy was associated with increased rates of response (relative risk $(\mathrm{RR})=1.30,95 \% \mathrm{C}$ 1.16-1.44, number needed to treat $(\mathrm{NNT})=10,95 \% \mathrm{Cl} 7-18)$ and remission $(\mathrm{RR}=1.51,95 \% \mathrm{Cl} 1.27-1.79, \mathrm{NNT}=8,95 \% \mathrm{Cl}$ 5-14) relative to placebo. Combination therapy was not statistically superior to monotherapy. Weight gain, switching and suicide rates did not differ between groups. No differences were found between individual medications or drug classes for any outcome.

\section{Conclusions}

Mood stabilisers are moderately efficacious for acute bipolar depression. Extant studies are few and limited by high rates of discontinuation and short duration. Further study of existing and novel agents is required.

\section{Declaration of interest}

G.M.M. has received honoraria, consulting fees or research support from Wyeth, AstraZeneca, Janssen, Lilly, Novartis, GlaxoSmithkline, Boerhinger, Oryx and Lundbeck.
Bipolar disorder is a chronic, recurrent neuropsychiatric disorder associated with immense suffering and high healthcare costs. ${ }^{1}$ Despite the fact that the occurrence of manic episodes are the defining feature of bipolar I disorder, individuals spend a larger proportion of their lives in a depressed state., ${ }^{2,3}$ Whereas much recent attention has focused on whether there is a role for antidepressant medications in people with bipolar disorder, the quality of evidence supporting the efficacy and tolerability of alternative treatments for bipolar depression has received little scrutiny. A systematic review of antidepressants in people with bipolar disorder concluded that they are effective and unlikely to cause mood switching in the short term. ${ }^{4}$ However, some have expressed concerns that these agents do increase switch rates and destabilise the long-term clinical course. ${ }^{5}$ A systematic appraisal and meta-analysis of the benefits and drawbacks of treating bipolar depression with mood stabilisers can aid clinicians and regulatory bodies in making evidence-based decisions regarding the care of these individuals.

Given this background, we set out to examine the efficacy, acceptability and safety of mood stabiliser monotherapy in the acute treatment of major depressive but not mixed episodes in adults with bipolar disorder, compared with placebo and with other active comparators. This included assessing rates of response and remission, all-cause discontinuation, affective switching, weight gain and suicidal behaviour. We also explored whether differences in treatment effects were related to medication type or individuals' baseline clinical features.

\section{Method}

\section{Search strategy}

We searched MEDLINE (from 1950 to week 2 of January 2008), EMBASE (from 1980 to week 4 2008), PsycINFO (from 1967 to week 2 January 2008), CINAHL (from 1982 to week 2 January
2008), the Cochrane Central Register of Controlled Trials and the Cochrane Database of Systematic Reviews (1800-2008). We included randomised, double-blind controlled trials in any language covered by the above sources. The subject headings applicable to each of the above medical literature databases can vary. Thus, subject headings or keywords relevant to the disorder, treatments and methodological features of interest specific to each database were used and combined in consultation with a librarian experienced in conducting systematic reviews. These included the terms for bipolar disorder and depression that were combined with the Boolean operator OR, and then combined using the term AND with [lithium OR valproic acid OR carbamazepine OR lamotrigine $\mathrm{OR}$ topiramate $\mathrm{OR}$ gabapentin $\mathrm{OR}$ all benzodiazepines $\mathrm{OR}$ all typical antipsychotics $\mathrm{OR}$ aripiprazole $\mathrm{OR}$ clozapine OR olanzapine OR quetiapine OR risperidone OR ziprasidone]. The terms adult AND randomised clinical trial were then combined, and, using the operator AND, were added to the above disorder and treatment-specific search terms.

We also monitored the table of contents of the British Journal of Psychiatry, the Journal of Clinical Psychiatry, New England Journal of Medicine, The Lancet, the Archives of General Psychiatry, the American Journal of Psychiatry, Bipolar Disorders and the Journal of Affective Disorders up to 1 April 2008 for further reports. Moreover, we reviewed reference lists of acquired studies and searched the clinical trials database at www.clinicaltrials.gov.

Titles and abstracts of all studies were reviewed by both authors. Articles were selected for full-text review if inclusion criteria were met or if uncertainty regarding their eligibility existed. Disagreements at any stage of article selection were resolved by discussion between the two reviewers and if agreement could not be reached, a third reviewer was recruited to determine eligibility. Initial agreement between the initial two reviewers was calculated using the $\Phi$ statistic $^{6}$ as it is superior to weighted kappa in cases where agreement is particularly high or low. All 
disagreements were resolved by discussion; and intervention by the third reviewer was not required.

\section{Study eligibility}

We included all published, randomised, placebo-controlled and active comparator trials described as double-blind and that included a mood stabiliser treatment group in adults (aged 18-65) with bipolar disorder and acute major depression. Acute in this context refers to treatments administered to reduce symptoms of an existing episode of depression and that continued until the depressive episode was in remission or the study ended. Studies were eligible regardless of whether participants were medication free or not at baseline.

Studies also had to meet a methodological quality threshold, which we set at a score of three or more on the Jadad scale. ${ }^{7}$ This instrument awards one point to a study if it is described as randomised, another if it is double-blind and an additional point if there is a description of withdrawals and individuals who drop out. Studies also receive one point if the method used to generate the randomisation sequence is described and appropriate and/or if the method of double-blinding is described and appropriate. One point is deducted for each of inappropriate application of randomisation or double-blinding. In keeping with suggestions regarding the assessment of articles about therapy, ${ }^{8}$ an extra point was given if participants were analysed in the groups to which they were randomised. This occurred only after inclusion based on the original five-point scale was determined. Despite the fact that questions exist regarding the validity of utilising scale scores in systematic reviews, ${ }^{9}$ the Jadad measure was utilised because it has been widely used and is well-recognised. Its utilisation reflects our desire to convey a concise but meaningful description of the methodological quality criteria applied to study selection for practising healthcare professionals. The overall quality of the evidence for each outcome was assessed according to grades of recommendation, assessment, development and evaluation (GRADE) working group criteria. ${ }^{10}$

If studies contained diagnostically heterogeneous populations, we required that data be reported separately for people with bipolar disorder. Studies examining lithium, valproic acid, carbamazepine, lamotrigine, topiramate, gabapentin, the benzodiazepines and the typical and atypical antipsychotics were eligible for consideration if the medications were started during the depressive phase of bipolar disorder. Medication dosages could be fixed or flexible. Eligible studies could contain participants who were not taking other medications at baseline as well as those in which the investigational medication was added to ongoing treatment.

We did not include studies that examined participants in mixed states. Most studies that have enrolled individuals in mixed states focus on the treatment of mania and fail to report data separately for mixed and manic groups. Crossover trials were excluded because mood stabilisers are likely to exert therapeutic effects beyond their cessation. Despite the fact that the mood stabilisers as a class represent a pharmacologically heterogeneous class of medication, results were pooled and then the effects of separate medications and medication classes were explored in subsequent sensitivity analyses. Data were extracted independently by both authors using a predetermined data extraction form and disagreements were discussed. If no consensus could be reached a third reviewer extracted data and those results were used. Double entry of the data by both authors prevented the need for involvement by the third reviewer.

\section{Data analysis}

Data were double entered by each author into RevMan 4.2 for Windows (Nordic Cochrane Centre, Copenhagen, www. cc-ims.net/) for analysis. Mood stabiliser monotherapy was compared with placebo, with combination therapy (mood stabiliser plus another pharmacological agent) initiated at the same time as mood stabiliser monotherapy and to antidepressant add-on or monotherapy in separate analyses for each outcome. These outcomes included rates of response, remission, all-cause discontinuation (a proxy for the acceptability of treatment to individuals), affective switching, suicidal behaviour and clinically significant weight gain. All outcomes were dichotomous and so pooled relative risks (RR) with $95 \%$ confidence intervals were calculated. For treatment response and remission, relative risks above one represent an increased likelihood of a positive outcome (response or remission) for mood stabiliser monotherapy relative to comparators. For adverse events (affective switching, suicidal behaviour and weight gain), relative risks above one indicated that mood stabilisers posed a greater risk than their respective comparators. All attempts to utilise intention-to-treat data were made for studies that contained information relevant to the outcomes of interest. We did not impute values for efficacy or safety outcomes and defined the total number of participants eligible for efficacy and safety analyses in each trial as those who had had at least one post-baseline assessment value. When data were not reported in studies, authors were contacted. If no reply was received, values were estimated based on figures in the manuscript.

Meta-analysis using the random-effects method of DerSimonian \& Laird $^{11}$ was undertaken. This approach assumes that included studies represent a random sample of a larger population of studies and takes into account the possibility that studies that could be included are underway or not yet published. ${ }^{12}$ Indeed, our search of www.clinicaltrials.gov using the term bipolar disorder and then depression indicated that 14 registered trials that may meet inclusion criteria for this review are currently in progress.

The presence of heterogeneity between studies for each outcome was tested for by visual inspection of forest plots and supplemented with Cochran's $Q$ statistic. ${ }^{13}$ The magnitude of heterogeneity for each outcome was determined using the $I^{2}$ statistic. $^{14}$ If statistical heterogeneity was present, reflected by a $Q$-test $P<0.05$ (two-tailed), additional post hoc subgroup analyses were undertaken to attempt to understand reasons for it. A priori sensitivity analyses were applied to placebo-controlled studies alone because active comparator trials used a wide variety of treatments and sample sizes for these comparisons were smaller, further reducing the power to detect meaningful differences. The sensitivity analyses conducted sought to examine whether treatment effect sizes differed between each of the individual medications, antipsychotic and anticonvulsant classes, bipolar type, gender or those with psychotic features or a rapid cycling course. Unfortunately, papers included in the meta-analysis only contained data that permitted comparisons between individual medications and between medication classes. For these comparisons, tests of interaction ${ }^{15}$ were conducted to compare the levels of each characteristic for each outcome (e.g. lamotrigine $v$. olanzapine; antipsychotics $v$. anticonvulsants), as per the method of Altman \& Bland. ${ }^{15}$ Tests of interaction are used to compare two independent estimates of the same quantity (in this case, relative risks) from separate analyses. Significance levels for these comparisons were set at 0.01 (two-tailed) rather than the 0.005 generated by the Bonferroni correction, as it was felt to unduly reduce the power to detect effects. Number needed to treat (NNT) or number needed to harm $(\mathrm{NNH})$ statistics were calculated using Visual $\mathrm{Rx}$ for Windows (Cates, www.nntonline. net) using relative risks and designating the median value of the control/comparator groups for each outcome as the control event rate. These were only calculated when relative risks were significant. 
There is uncertainty regarding the best means of detecting publication bias and no current method is universally accepted because of problems with unreliability and low power. ${ }^{16}$ Publication bias is, however, an area of increasing concern in clinical trials research, particularly in psychiatry. ${ }^{17}$ Thus, despite its limitations, a decision was made to examine funnel plots visually as a means of assessing publication bias in cases where ten or more studies were present. If these plots were clearly asymmetric or analysis was not possible, they were classified as having possible publication bias; otherwise publication bias was deemed to be unlikely.

\section{Results}

\section{Search findings}

In keeping with the quality of reporting meta-analyses statement, ${ }^{18}$ a trial flow summary is included (Fig. 1). Fifteen publications representing 18 unique studies, ${ }^{19-33}$ containing 4105 randomised participants were eligible. All studies used DSM criteria except Fieve and colleagues, ${ }^{30}$ which relied on the then current clinical criteria for diagnosis.

Twelve studies were multisite and six recruited participants from a single centre. The number of participants in these studies varied from 19 to 833 . Of the 12 studies containing data eligible for placebo-controlled comparisons, 5 examined lamotrigine, 1 carbamazepine, 2 valproic acid, 2 olanzapine and 2 quetiapine. Studies followed patients from 3 to 26 weeks, although the majority were 6-8 weeks in duration. Fifteen contained participants with a diagnosis of bipolar disorder type I or II only and three also contained those with bipolar disorder NOS (not otherwise specified). None of the eligible studies reported results for all relevant outcomes separately for different bipolar types, rapid cycling or psychotic participants or by gender. Six studies were not directly sponsored by a pharmaceutical company. Only two were prospectively registered in a clinical trials registry. Jadad scale scores ranged from three to six. Overall quality of the evidence for all outcomes assessed according to GRADE working group criteria was moderate, mainly because of high rates of drop out in both treatment and comparator groups in the trials. Funnel plots could only be examined for clinical response in the mood stabilising $v$. placebo comparison and suggested that publication bias was unlikely. For the remainder we concluded that publication bias may exist. Remaining features of all studies contributing data to this review are contained in online Table DS1. Results of the meta-analysis and a summary of the quality of the evidence for each outcome are found in Table 1.

\section{Comparison 1: mood stabiliser monotherapy v. placebo}

Of the 12 studies containing data eligible for placebo-controlled comparisons, ${ }^{19-27} 5$ examined lamotrigine, 1 carbamazepine, 2 valproic acid, 2 olanzapine and 2 quetiapine.

\section{Clinical response}

Of 12 studies, 10 were eligible ${ }^{19,20,22,24-27}$ and contained data on 2864 participants for the assessment of clinical response. Of these, four studies defined response as a $50 \%$ or greater reduction in baseline Montgomery-Åsberg Depression Rating Scale (MADRS) score alone. ${ }^{20,22,24,25}$ Four used the same criteria but required in addition that the Hamilton Rating Scale for Depression (HRSD) baseline score was also reduced by $50 \%$ or more and that the Clinical Global Impressions - Improvement (CGI-I) scale be much or very much improved. ${ }^{27}$ One required a HRSD score reduction of $50 \%$ or more from baseline $e^{26}$ and another $\geqslant 50 \%$

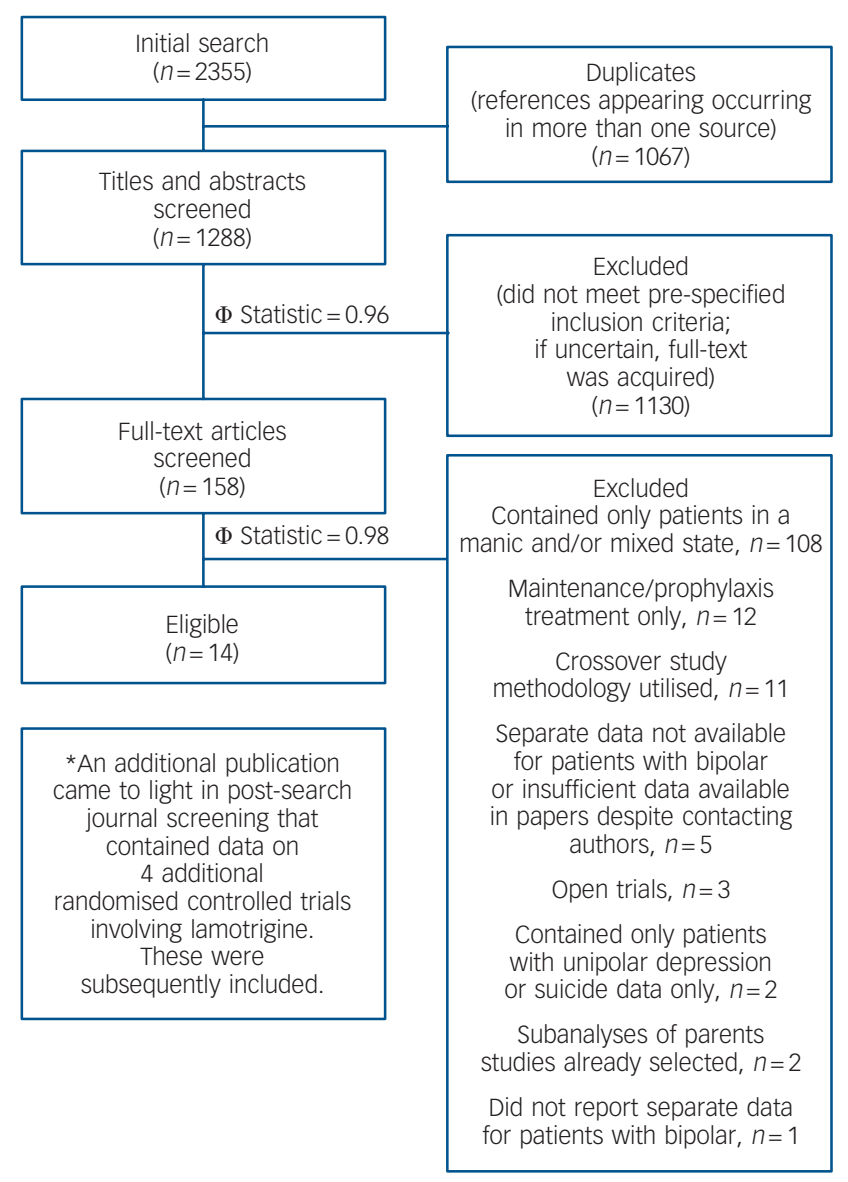

Fig. 1 Study flow diagram.

reduction from baseline score on MADRS or HRSD (17-item) or a CGI-I of much or very much improved. ${ }^{19}$ Participants randomised to mood stabiliser monotherapy were more likely to demonstrate clinical response than those taking placebo $(\mathrm{RR}=1.30,95 \%$ CI 1.16-1.44, NNT $=10,95 \%$ CI 7-18; Fig. 2). No single medication or medication class (antipsychotics $v$. anticonvulsants) demonstrated statistical superiority over another.

\section{Symptom remission}

Four studies ${ }^{20-22,24}$ with 1707 participants provided remission data. Three defined this as an end-point MADRS score of 12 or less ${ }^{20,22,24}$ and one a HRSD score of less than nine along with a $50 \%$ or greater decline in score from baseline. ${ }^{21}$ Rates of remission in those randomised to mood stabiliser monotherapy were significantly greater than those taking placebo $(\mathrm{RR}=1.51,95 \%$ CI $1.27-$ 1.79, NNT $=8,95 \%$ CI 5-14; Fig. 3). There were no differences between medications or medication classes on this outcome.

\section{Acceptability}

Data on 3053 participants from all but one study ${ }^{23}$ were available for an assessment of all-cause discontinuation, our definition of treatment acceptability for all comparisons. Mood stabiliser monotherapy was not associated with a statistically significant increase or decrease in all-cause discontinuation relative to placebo $(\mathrm{RR}=1.00,95 \% \mathrm{CI} 0.87-1.1)$. Again, there were no medication or class differences for this outcome.

\section{Affective switch}

In the included studies for all comparisons (mood stabiliser $v$. placebo, mood stabiliser $v$. combination therapy, and mood 


\begin{tabular}{|c|c|c|c|c|c|}
\hline & $\begin{array}{l}\text { Participants, } n \\
\quad \text { (studies, } n \text { ) }\end{array}$ & $\begin{array}{l}\text { Effect size } \\
\text { Relative risk } \\
(95 \% \mathrm{Cl})\end{array}$ & $\begin{array}{l}\text { Number } \\
\text { needed } \\
\text { to } \text { treat }^{a}\end{array}$ & $\begin{array}{l}\text { Number } \\
\text { needed } \\
\text { to harm }\end{array}$ & $\begin{array}{c}\text { Quality of the evidence } \\
\text { and methodological } \\
\text { limitations }^{\mathrm{b}}\end{array}$ \\
\hline $\begin{array}{l}\text { Response } \\
\text { Mood stabiliser } v \text {. placebo } \\
\text { Mood stabiliser } v \text {. combination of mood stabiliser } \\
\text { and additional agent } \\
\text { Mood stabiliser } v \text {. antidepressant }\end{array}$ & $\begin{array}{r}2864(10) \\
1305(5) \\
39(2)\end{array}$ & $\begin{array}{l}1.30(1.16-1.44) \\
0.85(0.71-1.02) \\
0.88(0.41-1.91)\end{array}$ & $10(7-18)$ & & $\begin{array}{l}\text { Serious limitations }(-1)^{\mathrm{c}} \\
\text { Serious limitations }(-2)^{\mathrm{d}} \\
\text { Serious limitations }(-2)^{\mathrm{d}}\end{array}$ \\
\hline $\begin{array}{l}\text { Remission } \\
\text { Mood stabiliser } v \text {. placebo } \\
\text { Mood stabiliser } v \text {. combination of mood stabiliser } \\
\text { and additional agent } \\
\text { Mood stabiliser } v \text {. antidepressant }\end{array}$ & $\begin{array}{r}1707(4) \\
1212(4) \\
39(2)\end{array}$ & $\begin{array}{l}1.51(1.27-1.79) \\
0.84(0.65-1.10) \\
0.55(0.21-1.41)\end{array}$ & $8(5-14)$ & & $\begin{array}{l}\text { Serious limitations }(-1)^{\mathrm{c}} \\
\text { Serious limitations }(-2)^{\mathrm{d}} \\
\text { Serious limitations }(-2)^{\mathrm{d}}\end{array}$ \\
\hline $\begin{array}{l}\text { Acceptability/all-cause discontinuation } \\
\text { Mood stabiliser } v \text {. placebo } \\
\text { Mood stabiliser } v \text {. combination of mood stabiliser } \\
\text { and additional agent } \\
\text { Mood stabiliser } v \text {. antidepressant }\end{array}$ & $\begin{array}{r}3053(11) \\
1351(5) \\
77(3)\end{array}$ & $\begin{array}{l}1.00(0.87-1.1) \\
1.14(0.97-1.34) \\
1.46(0.47-4.57)\end{array}$ & & & $\begin{array}{l}\text { Serious limitations }(-2)^{\mathrm{d}} \\
\text { Serious limitations }(-2)^{\mathrm{d}} \\
\text { Serious limitations }(-2)^{\mathrm{d}}\end{array}$ \\
\hline $\begin{array}{l}\text { Switch to mania or hypomania } \\
\text { Mood stabiliser } v \text {. placebo } \\
\text { Mood stabiliser } v \text {. combination of mood stabiliser } \\
\text { and additional agent } \\
\text { Mood stabiliser } v \text {. antidepressant }\end{array}$ & $\begin{array}{r}2883(10) \\
1209(5) \\
66(3)\end{array}$ & $\begin{array}{l}0.77(0.54-1.10) \\
1.08(0.69-1.68) \\
0.67(0.09-4.95)\end{array}$ & & & $\begin{array}{l}\text { Serious limitations }(-2)^{\mathrm{d}} \\
\text { Serious limitations }(-2)^{\mathrm{d}} \\
\text { Serious limitations }(-2)^{\mathrm{d}}\end{array}$ \\
\hline $\begin{array}{l}\text { Suicidal behaviours } \\
\text { Mood stabiliser } v \text {. placebo } \\
\text { Mood stabiliser } v \text {. combination of mood stabiliser } \\
\text { and additional agent }\end{array}$ & $\begin{array}{l}1919(6) \\
863(4)\end{array}$ & $\begin{array}{l}0.45(0.09-2.21) \\
6.35(0.77-52.22)\end{array}$ & & & $\begin{array}{l}\text { Serious limitations }(-2)^{\mathrm{d}} \\
\text { Serious limitations }(-2)^{\mathrm{d}}\end{array}$ \\
\hline $\begin{array}{l}\text { Weight gain of } \geqslant 7 \%^{8} \\
\quad \text { Mood stabiliser } v \text {. placebo }\end{array}$ & $1612(3)$ & $6.11(1.43-26.07)$ & & $11(3-130)$ & Serious limitations $(-3)^{\mathrm{e}}$ \\
\hline $\begin{array}{l}\text { a. Number needed to treat only calculated when relative risks } \\
\text { b. Methodological quality assessed according to GRADE criteria } \\
\text { c. Large loss to follow-up. } \\
\text { d. Large loss to follow-up, lack of precision in estimate of effec } \\
\text { e. Large loss to follow-up, lack of precision in estimate of effec } \\
\text { f. No events for comparison in mood stabilisers } v \text {. antidepress } \\
\text { g. No data available for mood stabilisers } v \text {. antidepressant or }\end{array}$ & $\begin{array}{l}\text { significant. } \\
\text { for all outcomes of } \mathrm{i} \\
\text { sible publication bias } \\
\text { sible publication bias } \\
\text { up. } \\
\text { tabilisers } v \text {. combina }\end{array}$ & $\begin{array}{l}\text { rest was rated as moc } \\
\text { d significant heteroge } \\
\text { of mood stabiliser ar }\end{array}$ & te. & & \\
\hline
\end{tabular}

stabiliser $v$. antidepressants), switch into a manic, mixed or hypomanic state during the trial was typically defined using the development of symptoms meeting DSM-IV-TR criteria. For the mood stabiliser $v$. placebo comparison, data on treatment emergent mania, mixed or hypomanic states were available for ten studies $^{19-22,24,25,27}$ containing 2883 participants. Compared with placebo, individuals treated with mood stabiliser monotherapy were no more or less likely to undergo an affective switch ( $R R=0.77,95 \%$ CI $0.54-1.10$ ). No medication or class of medications posed a significantly increased or decreased risk of this outcome.

\section{Suicidal behaviour}

This outcome was defined as all noted and reported cases of suicide attempts and completions. Six studies containing 1919 participants reported relevant data. ${ }^{19-22,24,25}$ Mood stabilisers were not associated with increased rates of suicidal behaviour relative to placebo $(\mathrm{RR}=0.4595 \%$ CI $0.09-2.21)$. No agent or class posed more or less risk for suicidal behaviour than another.

\section{Clinically significant weight gain}

There was significant heterogeneity in the three studies that contributed to the analysis of clinically significant weight gain. Atypical antipsychotics were the only agents used in these trials ${ }^{20,22,24}$ and were associated with an increased risk relative to placebo $(\mathrm{RR}=6.11,95 \% \mathrm{CI} 1.43-26.07 ; \mathrm{NNH}=11,95 \% \mathrm{CI}$ $3-130)$. This heterogeneity could be explained by medication type as there was a trend towards increased rates of weight gain of 7\% or more in trials where participants were given olanzapine relative to quetiapine, although this did not reach our pre-specified level of significance for tests of interaction (ratio of $\mathrm{RR}=10.95,95 \%$ CI 1.28-93.55, $P=0.03$ ).

\section{Comparison 2: mood stabiliser monotherapy v. combination therapy}

Six studies involving 1322 participants ${ }^{20,23,26,28,29,33}$ compared mood stabiliser monotherapy plus or minus placebo to combination treatments involving a mood stabiliser and an augmenting agent. This was an antidepressant in all cases but one. ${ }^{26}$ Only one added treatment to ongoing therapy. ${ }^{33}$ Sachs and colleagues' participants also received a psychosocial intervention, the effect of which did not differ between groups, ${ }^{29}$ but $18 \%$ of participants included in the monotherapy group were on more than one mood stabilising medication.

\section{Clinical response}

In the five studies and 1305 participants ${ }^{20,26,28,29,33}$ that permitted comparisons of clinical response rates of mood stabiliser monotherapy with combination pharmacotherapy, combination therapy was not superior to monotherapy ( $R R=0.85,95 \%$ CI $0.71-1.02)$. Criteria for response were comparable with those used in the mood stabiliser $v$. placebo comparisons. There was significant heterogeneity in the studies (Cochran's $Q=9.22, \quad P=0.03$; $\left.I^{2}=67.5 \%\right)$ which is largely attributable to the different methodology employed by Sachs and colleagues. ${ }^{29}$ 
Review: Mood stabilisers in bipolar depression

Comparison: 14 Response by agent (mood stabiliser v. placebo)

Outcome: 01 Response by agent (mood stabiliser v. placebo)

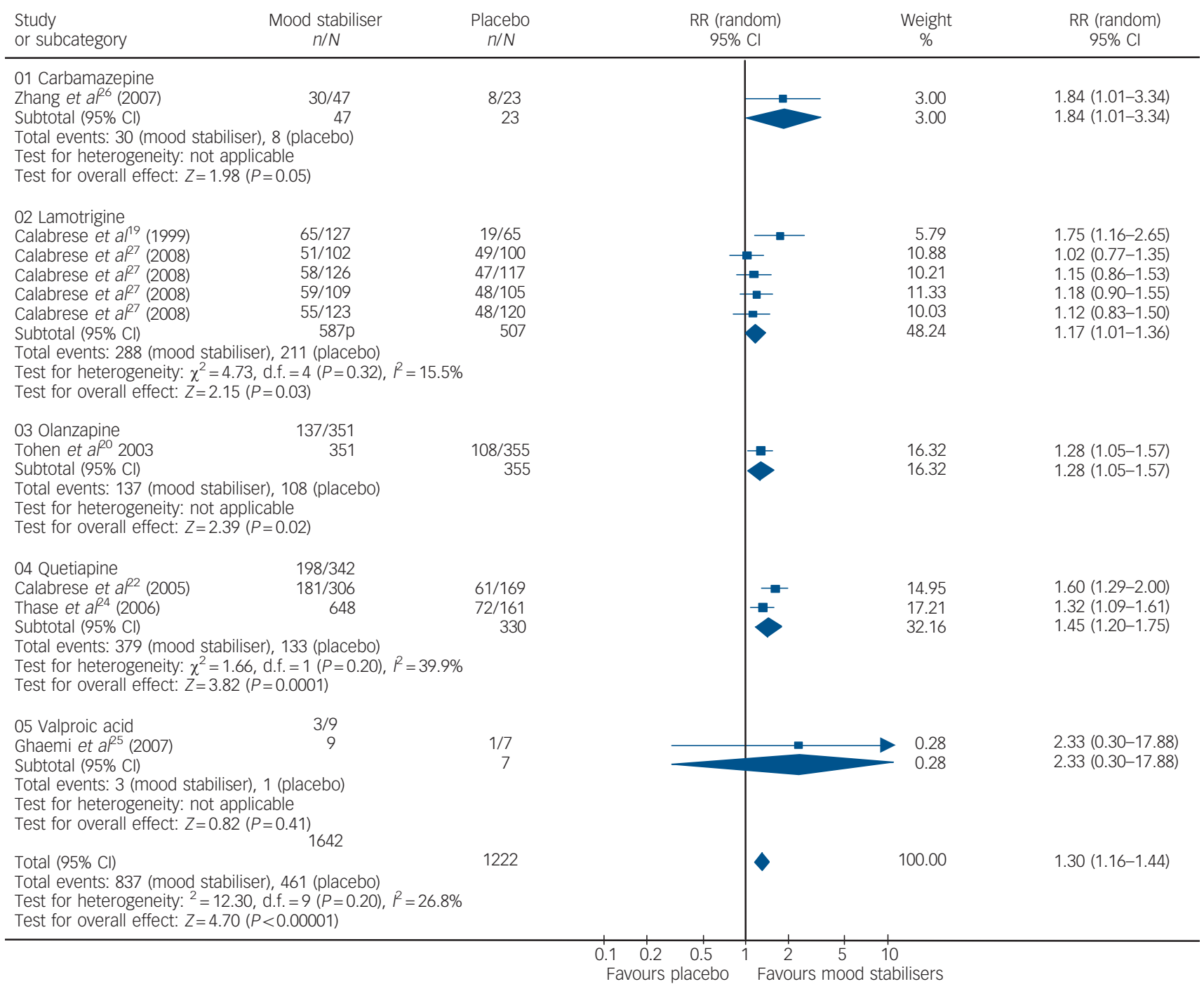

Fig. 2 Random effects model of clinical response in randomised controlled trials of mood stabilising medication $v$. placebo in the treatment of bipolar depression.

$N$, total number in study; $n$, number with outcome of interest; RR, relative risk, $\chi^{2}$, Cochran's $Q$ statistic.

\section{Symptom remission}

In the four studies (1212 participants) $20,28,29,33$ that permitted comparisons of remission rates between mood stabiliser monotherapy and combination treatment, combination therapy was neither superior nor inferior to treatment with mood stabilisers alone $(\mathrm{RR}=0.8495 \%$ CI $0.65-1.10)$. Again, criteria for remission were comparable with those used in the above mood stabiliser $v$. placebo comparisons.

\section{Acceptability}

Mood stabiliser monotherapy was not associated with a statistically significant increase or decrease in all-cause discontinuation relative with combination therapy in these five studies ${ }^{20,26,28,29,33}$ containing 1351 participants ( $\mathrm{RR}=1.14,95 \%$ CI $0.97-1.34)$.

\section{Safety}

In these comparisons, combination treatment was not associated with an increased risk of affective switch or suicidal behaviour relative with monotherapy ( $\mathrm{RR}=6.35,95 \%$ CI $0.77-52.22)$. There were no data for the weight gain outcome for this comparison.

\section{Comparison 3: mood stabiliser monotherapy $\mathbf{v}$. antidepressants}

Five studies ${ }^{23,30-33}$ involving only 106 participants compared mood stabilisers with antidepressants started during an acute major depressive episode and three involved participants already taking a mood stabiliser at baseline. ${ }^{31-33}$

\section{Clinical response and symptom remission}

Despite the use of similar response and remission definitions in these studies, there were no statistically significant differences in either response $(\mathrm{RR}=0.88,95 \%$ CI $0.41-1.91)$ or remission $(\mathrm{RR}=0.55,95 \%$ CI $0.21-1.41)$ rates between treatments in the two studies ${ }^{32,33}$ (39 participants) that provided data on participants who developed depression despite baseline mood stabiliser therapy and received add-on antidepressant or mood stabiliser treatment. 
Review: Mood stabilisers in bipolar depression

Comparison: 15 Response by agent (mood stabiliser v. placebo)

Outcome: $\quad 01$ Response by agent (mood stabiliser v. placebo)

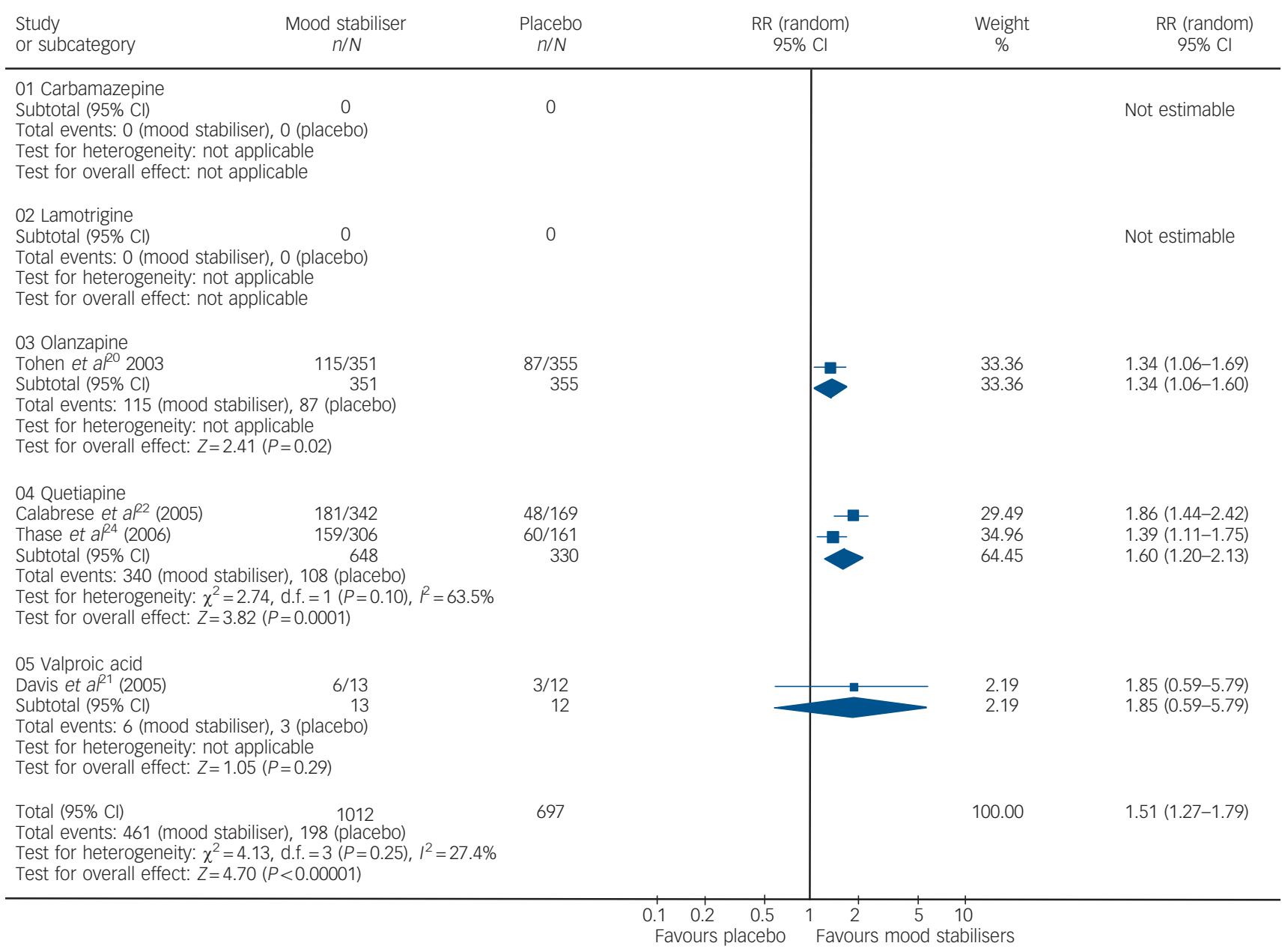

Fig. 3 Random effects model of symptom remission in randomised controlled trials of mood stabilising medication v. placebo in the treatment of bipolar depression.

$N$, total number in study; $n$, number with outcome of interest; RR, relative risk, $\chi^{2}$, Cochran's $Q$ statistic.

\section{Acceptability}

Treatment acceptability was not significantly different between mood stabiliser as add-on treatment when compared with antidepressant add-on in the three studies ${ }^{31-33}$ and 77 participants eligible for this analysis $(\mathrm{RR}=1.46,95 \%$ CI $0.47-4.57)$.

\section{Safety}

In these comparisons, antidepressant treatment was not associated with an increased risk of affective switch relative to mood stabiliser monotherapy ( $\mathrm{RR}=0.67,95 \%$ CI $0.09-4.95)$. There were no cases in this comparison for the suicidal behaviour or weight gain outcomes.

\section{Discussion}

\section{Main findings}

When medications were examined in the aggregate, the efficacy of mood stabiliser monotherapy was superior to placebo in the treatment of acute episodes of bipolar depression. Furthermore, monotherapy with mood stabilising medications appears to have equivalent efficacy to combination or antidepressant therapy in the acute treatment of this phase of bipolar disorder. Mood stabilisers were not less acceptable to participants than placebo for the acute treatment phase. Although limited by a short duration of follow-up and small number of events overall, we also observed no differences in terms of affective switching or suicidal behaviour between mood stabilising medications and placebo or other active treatment groups. In the mood stabiliser $v$. placebo comparison, no individual agent or class of medication was superior to another for any outcome. It should be noted however that the tests of interaction underlying this conclusion may have been underpowered to detect differences. Few studies are available comparing the use of mood stabilisers or antidepressants as add-on treatments for bipolar depression. These small sample sizes also limit the conclusions that can be drawn from comparisons between these treatment options. The quality of the evidence that supports the findings for all outcomes in this systematic review is moderate only, largely because of high rates of loss to follow-up in the trials.

\section{Clinical implications}

Although our systematic review supports the recommendations of more recently published practice guidelines that suggest that 
lamotrigine or quetiapine be considered as first-line agents for the treatment of acute bipolar depression, ${ }^{34,35}$ randomised, doubleblind, placebo-controlled trials suggest that olanzapine and carbamazepine monotherapy may also have utility for this indication. Caution should be exercised however in comparing the effect size estimates for the agents contained in this study with Gijsman and colleagues' systematic review of antidepressant treatment for bipolar depression ${ }^{4}$ since this would be an indirect comparison. Direct comparisons of these therapies such as those contained in Sachs and colleagues' work $^{29}$ provide a stronger basis for inference. However, available evidence suggests that combination therapy with antidepressants fails to outperform mood stabiliser monotherapy, which is relevant to decisions about the role of antidepressant medication in bipolar disorder. Overall, the included studies suggest that there are mood stabilising agents available to treat acute episodes of bipolar depression without increasing the risk of switching and without adding an unacceptable side-effect burden. Given these data and the uncertainty regarding the safety and utility of antidepressant medications in bipolar depression, at the present time there appears to be little support for the first-line use of antidepressant medications in the treatment of an acute episode of bipolar depression unless there are specific reasons why the mood stabilising medications examined here could not be used for individual patients. However, it is also important to acknowledge that head-to-head trials comparing mood stabilising medications against antidepressant medications in bipolar depression are few in number and somewhat contradictory in their findings, perhaps because of small samples sizes and different approaches. Indeed, more study is required to determine the role and optimal use of antidepressants in bipolar depression

The time-limited nature of the trials conducted to date makes it difficult to generalise to the long-term treatment of people with bipolar disorder, where maintenance treatment is a key component of the overall treatment approach. Another limitation of the data is that the majority of participants in the studies had bipolar disorder type I, and it is therefore impossible to know whether the effect of these treatments would be similar in people with type II bipolar disorder.

Unfortunately, the design and reporting of the original trials did not allow us to calculate separate effect sizes for the different genders, or for individuals with psychotic features or a rapid cycling course.

Whereas clinical practice guidelines also frequently list lithium as a first-line treatment for bipolar depression, only one parallel group randomised trial involving lithium was eligible for inclusion in the current review. Although a number of randomised, masked crossover studies that have examined the efficacy of lithium for bipolar depression exist, they were not included in our systematic review because of the difficulties associated with their interpretation owing to the probable carryover effects of lithium treatment into placebo periods. We were however able to locate eight published masked, placebo-controlled trials ${ }^{36}$ and two active treatment ${ }^{30,37}$ comparison studies containing outcome data for lithium treatment of bipolar depression for 174 participants. All but one has been interpreted as indicating a benefit for lithium over placebo.

Despite the established role of lithium as the gold standard mood stabilising medication, and its apparent anti-suicide properties, it is worth noting that high-quality trials confirming its efficacy in the short-term treatment of bipolar depression are limited. Furthermore, there is a significant absence of data informing clinicians how to treat participants who become depressed while on therapeutic doses of lithium.

Given that rates of clinical response are usually higher than remission, our finding that the NNT for response to mood stabiliser monotherapy $v$. placebo was greater than the NNT for remission seems counterintuitive. Closer examination of the data shows that in the studies that comprise the remission data, the percentage of participants remitting in the active treatment groups were lower than the rates of response. This is in keeping with what might be expected based on clinical experience and existing trial data. However, remission rates in the control groups of these studies were much lower than those for response, which led to the higher relative likelihood of remission compared with response (and subsequently, lower NNTs). The finding that fewer participants need treatment to achieve remission than response is likely because of the fact that the studies that reported remission data were among those with the highest remission and response rates. In other words, the studies that were included in the remission analysis were not a random sample of all studies. These studies actually had unusually high rates of treatment success (response and remission) and thus were not broadly representative of all studies that compared mood stabilisers with placebo.

One possible criticism of the current study is the appropriateness of synthesising data on a group of pharmacologically heterogeneous agents. Although this was considered, it was felt that classifying them as a single group was a reasonable strategy given that there is little evidence of striking differences in the success rates of treating bipolar depression with these agents. This decision was further supported by the absence of significant differences between individual drugs in our own sensitivity analyses.

Overall, the results of this systematic review and meta-analysis support the use of mood stabilising medications as first-line treatments for people with acute bipolar depression. Studies examining combination treatments are urgently required as there are few studies to guide treatment decisions when individuals become depressed while on mood stabilising medications. The modest effect sizes observed in studies of each class of medication examined, however, suggest that simply optimising or combining currently available medications is unlikely to eliminate the morbidity associated with this phase of illness. Novel treatments, both pharmacological and otherwise, are required for the depressed phase of bipolar disorder.

Ryan J. Van Lieshout, MD, Glenda M. MacQueen, MD, PhD, Department of Psychiatry and Behavioural Neurosciences, McMaster University, Hamilton, Canada

Correspondence: Glenda M. MacQueen, Department of Psychiatry, Foothills Medical Centre, 1403-29th Street, NW, Calgary, AB, Canada T2N 2T9. Email: gmmacque@ucalgary.ca

First received 22 Jul 2008, final revision 2 Jun 2009, accepted 2 Dec 2009

\section{References}

1 Simon GE, Unutzer J. Health care utilization and costs among patients treated for bipolar disorder in an insured population. Psychiatr Serv 1999; 50: 1303-8.

2 Judd LL, Akiskal HS, Schlettler PJ, Endicott J, Maser J, Solomon DA, et al. The long-term natural history of the weekly symptomatic status of bipolar I disorder. Arch Gen Psychiatry 2002; 59: 530-7.

3 Judd LL, Akiskal HS, Schlettler PJ, Coryell W, Endicott J, Maser J, et al. A prospective investigation of the natural history of the long-term weekly symptomatic status of bipolar II disorder. Arch Gen Psychiatry 2003; 60: 261-9.

4 Gijsman HJ, Geddes JR, Rendell JM, Nolen WA, Goodwin GM. Antidepressants for bipolar depression: a systematic review of randomized controlled trials. Am J Psychiatry 2004; 161: 1537-47.

5 Goldberg JF, Truman CJ. Antidepressant-induced mania: an overview of current controversies. Bipolar Disord 2003; 5: 407-20.

6 Meade MO, Cook RJ, Guyatt GH, Groll R, Kachura JR, Bedard M, et al. Interobserver variation in interpreting chest radiographs for the diagnosis 
of acute respiratory distress syndrome. Am J Respir Crit Care Med 2000; 161 85-90.

7 Jadad AR, Moore RA, Carroll D, Jenkinson C, Reynolds DJ, Gavaghan DJ, et al. Assessing the quality of reports of randomized clinical trials: is blinding necessary? Control Clin Trials 1996; 17: 1-12.

8 Guyatt GH, Rennie D and the American Medical Assocation Evidence-Based Medicine Working Group. Users' Guide to the Medical Literature: Essentials of Evidence-Based Practice. AMA Press, 2002.

9 Juni $\mathrm{P}$, Witschi A, Bloch R, Egger M. The hazards of scoring the quality of clinical trials for meta-analysis. JAMA 1999; 282: 1054-60.

10 Schunemann HJ, Jaeschke R, Cook DJ, Bria WF, El-Solh AA, Ernst A, et al. An Official ATS Statement: grading the quality of evidence and strength of recommendations in ATS guidelines and recommendations. Am J Respir Crit Care Med 2006; 174: 605-14.

11 DerSimonian R, Laird N. Meta-analysis in clinical trials. Control Clin Trials 1986; 7: 177-88.

12 Fleiss JL. The statistical basis of meta-analysis. Stat Methods Med Res 1993 2: $121-45$.

13 Cochran WG. The combination of estimates from different experiments. Biometrics 1954; 10: 101-29.

14 Higgins JPT, Thompson SG, Deeks JJ, Altman DG. Measuring inconsistency in meta-analyses. BMJ 2003; 327: 557-60.

15 Altman DG, Bland JM. Interaction revisited: the difference between two estimates. BMJ 2003; 326: 219.

16 Gavaghan DJ, Moore RA, McQuay JH. An evaluation of homogeneity tests in meta-analyses in pain using simulations of individual patient data. Pain 2000; 85: 415-24.

17 Turner EH, Matthews AM, Linardatos E, Tell RA, Rosenthal R. Selective publication of antidepressant trials and its influence on apparent efficacy. New Engl J Med 2008; 358: 252-60.

18 Moher D, Cook DJ, Eastwood S, Olkin I, Rennie D, Stroup DF. Improving the quality of reports of meta-analyses of randomized controlled trials: the QUOROM statement. Lancet 1999; 354: 1896-1900.

19 Calabrese JR, Bowden CL, Sachs GS, Ascher JA, Monahan E, Rudd GD. A double-blind placebo-controlled study of lamotrigine monotherapy in outpatients with bipolar I depression. J Clin Psychiatry 1999; 60: 79-88.

20 Tohen M, Vieta E, Calabrese J, Ketter TA, Sachs G, Bowden C, et al. Efficacy of olanzapine and olanzapine-fluoxetine combination in the treatment of bipolar I depression. Arch Gen Psychiatry 2003; 60: 1079-88.

21 Davis LL, Bartolucci A, Petty F. Divalproex in the treatment of bipolar depression: a placebo-controlled study. J Affect Disord 2005; 85: 259-66.

22 Calabrese JR, Keck Jr PE, Macfadden W, Minkwitz M, Ketter TA, Weisler RH, et al. A randomized, double-blind, placebo-controlled trial of quetiapine in the treatment of Bipolar I or II depression. Am J Psychiatry 2005; 162: $1351-60$.
23 Amsterdam JD, Shults J. Comparison of fluoxetine, olanzapine, and combined fluoxetine and olanzapine initial therapy of bipolar type I and type II major depression-lack of manic induction. J Affect Disord 2005; 87: 121-30.

24 Thase ME, Macfadden W, Weisler RH, Chang W, Paulsson B, Khan A, et al. A double-blind, placebo-controlled study (The BOLDER II Study). J Clin Psychopharmacol 2006; 26: 600-9.

25 Ghaemi SN, Gilmer WS, Goldberg JF, Zablotsky B, Kemp DE, Kelley ME, et al. Divalproex in the treatment of acute bipolar depression: a preliminary double-blind, randomized, placebo-controlled pilot study. J Clin Psychiatry 2007; 68: 1840-4.

26 Zhang Z-J, Kang W-H, Tan Q-R, Li Q, Gao C-G, Zhang F-G, et al. Adjunctive herbal medicine with carbamazepine for bipolar disorders: a double-blind, randomized, placebo-controlled study. J Psychiatr Res 2007; 41: 360-9.

27 Calabrese JR, Huffman RF, White RL, Edwards S, Thompson TR, Ascher JA, et al. Lamotrigine in the acute treatment of bipolar depression: results of five double-blind, placebo-controlled clinical trials. Bipolar Disord 2008; 10 : 323-33.

28 Brown EB, McElroy SL, Keck PE, Deldar A, Adms DH, Togen M, et al. A 7-week, randomized, double-blind trial of olanzapine/fluoxetine combination versus lamotrigine in the treatment of bipolar I depression. J Clin Psychiatry 2006; 67: 1025-33.

29 Sachs GS, Nierenberg AA, Calabrese JR, Marangell LB, Wisniewski SR, Gyulai $\mathrm{L}$, et al. Effectiveness of adjunctive antidepressant treatment for bipolar depression. New Engl J Med 2007; 356: 1711-22.

30 Fieve RR, Platman SR, Plutchik RR. The use of lithium in affective disorders. I. Acute endogenous depression. Am J Psychiatry 1968; 125: 492-8.

31 Young LT, Joffe RT, Robb JC, MacQueen GM, Marriott M, Patelis-Siotis I. Double-blind comparison of addition of a second mood stabilizer versus and antidepressant to an initial mood stabilizer for treatment of patients with bipolar depression. Am J Psychiatry 2000; 157: 124-6.

32 Schaffer A, Zuker P, Levitt A. Randomized, double-blind pilot trial comparing lamotrigine versus citalopram for the treatment of bipolar depression. J Affect Disord 2006; 96: 95-9.

33 Shelton RC, Stahl SM. Risperidone and paroxetine given singly and in combination for bipolar depression. J Clin Psychiatry 2004; 65: 1715-9.

34 Yatham LN, Kennedy SH, O'Donovan C, Parikh SV, MacQueen G, McIntyre RS, et al. Canadian Network for Mood and Anxiety Treatments (CANMAT) guidelines for the management of patients with bipolar disorder: update 2007. Bipolar Disord 2006; 8: 721-39.

35 National Institute for Health and Clinical Excellence. NICE Clinical Guideline 38, Bipolar Disorder: The Management of Bipolar Disorder in Adults, Children and Adolescents, in Primary and Secondary Care. NICE, 2006.

36 Zornberg GL, Pope HG. Treatment of depression in bipolar disorder: new directions for research. J Clin Psychopharmacol 1993; 13: 397-408.

37 Mendels J, Secunda SK, Dyson WL. A controlled study of the antidepressant effects of lithium carbonate. Arch Gen Psychiatry 1972; 26: 154-7. 